\title{
Influence of hydrothermal conditions on the morphology and particle size of zinc oxide powder
}

\author{
Chung-Hsin Lu*, Chi-Hsien Yeh \\ Department of Chemical Engineering, National Taiwan University, Taipei, Taiwan, ROC
}

Received 6 May 1999; received in revised form 22 May 1999; accepted 1 July 1999

\begin{abstract}
Crystalline zinc oxide powder has been successfully prepared by adopting ammonia as the base source via the hydrothermal process at temperature $\geqslant 100^{\circ} \mathrm{C}$. The temperature for synthesizing $\mathrm{ZnO}$ powder is around $200^{\circ} \mathrm{C}$ lower than that of conventional heating process. The formation and growth $\mathrm{ZnO}$ powder under hydrothermal environment progress rapidly as soon as the temperature reaches $100^{\circ} \mathrm{C}$. Prolonging the reaction time at $100^{\circ} \mathrm{C}$ does not significantly influence the characteristics of obtained powder; however, raising the reaction temperature slightly reduces the particle size and the production yield of $\mathrm{ZnO}$ powder. On the other hand, as the $\mathrm{pH}$ of the starting solution increases from 9 to 12, the morphology of ZnO powder markedly varies from an ellipsoidal shape to a rod-like shape. In addition, the crystallinity and particle size of $\mathrm{ZnO}$ powder increase with rise in the $\mathrm{pH}$ of solutions, but the yield of production decreases. The reason for the variation of morphology and characteristics of obtained powder with pH mainly depends on the nucleation states occurring in the hydrothermal reaction. (C) 2000 Elsevier Science Ltd and Techna S.r.l. All rights reserved.
\end{abstract}

Keywords: D. Zinc oxide ( $\mathrm{ZnO}$ ); Hydrothermal processing; Morphology and particle size

\section{Introduction}

The characteristics of electronic and structural ceramics are markedly influenced by the technological parameters used in processing of the ceramic powder such as particle size, morphology, purity, and chemical composition. In general, using conventional solid state reaction to synthesize ceramics requires heat treatment at high temperature for enhancing the diffusivity between raw solid materials. The high temperature usually results in unfavorable grain growth of particles of the reaction products, thereby causing difficulty for powder to sinter. In additions, for ceramics containing volatile species, raising the heating temperature leads to result in more evaporation of volatile species and causes stoichiometric deviation in the composition of final products.

For improving the drawbacks of solid-state reaction, various kinds of solution processes (or so called softchemical processes) have been investigated. Among the

\footnotetext{
* Corresponding author. Tel.: +886-2-363-5230; fax: +886-2-362-
} 3040 . solution processing routes, recently the hydrothermal process has been proposed to be an effective method for synthesizing fine ceramic powder [1-9]. The hydrothermal process in general progresses in a closed system at a high autogeneous pressure. By the benefit of the closed system with high pressure, the required temperature for preparing ceramic powder can be greatly reduced because of enhanced reactivity of reactive species, and fine particles with high sinterability can be obtained. In addition, the evaporation of volatile species can be suppressed, and the stoichiometry of ceramics can be maintained.

$\mathrm{ZnO}$ is one of important ceramic materials, and has been found to have diversified applications in electronic devices such as gas sensors, varistors, and transducers. Different routes such as precipitation [10-12], spray pyrolysis [13], and thermal decomposition [14] have been utilized for preparing $\mathrm{ZnO}$ powder; however, only a few studies have focused on the hydrothermal synthesis $[15,16]$. This study was aimed at the hydrothermal preparation of $\mathrm{ZnO}$ particles using ammonia as the alkaline source. The effects of the reaction temperature and time on the microstructure and particle size of $\mathrm{ZnO}$ powder have been examined. In addition, the influence 
of the $\mathrm{pH}$ of starting solutions on the variation of crystal structure and the production yield of $\mathrm{ZnO}$ powder has also been investigated.

\section{Experimental}

Reagent grade zinc nitrate was adopted as the source material for zinc species. Zinc nitrate was dissolved in deionized water for preparing zinc cation solution. Ammonia solution was added into $0.5 \mathrm{M}$ zinc nitrate solution to precipitate zinc cations. For avoiding the influence of $\mathrm{NO}_{3}^{-1}$ anions on the formation of $\mathrm{ZnO}$ powder, the precipitates were filtered and washed repeatedly by deionized water to remove the residual $\mathrm{NO}_{3}^{-1}$ anions present in precipitates. After drying at $55^{\circ} \mathrm{C}$, the dried precipitates were used as precursors. The obtained precursors were introduced into a teflonlined autoclave apparatus first. To this, $250 \mathrm{ml}$ deionized water was added. The $\mathrm{pH}$ of the reaction system was adjusted by ammonia solution. When the $\mathrm{pH}$ was greater than 11, all precipitates were dissolved. During the hydrothermal reaction, the heating temperature ranged from 100 to $200^{\circ} \mathrm{C}$, the heating time ranged from 0.5 to $2 \mathrm{~h}$, and the heating rate was set to be $4^{\circ} \mathrm{C} / \mathrm{min}$. For enhancing the reactivity and homogeneity of reacting solutions, a mechanical stirrer was used, and the rotation speed of the stirrer was set at $300 \mathrm{rpm}$. After hydrothermal reaction, the reactor was cooled to room temperature, and the powder was collected by following filtration and drying processes.

The thermal behavior of the obtained precursors was investigated by thermogravimetry analysis (TGA). $\mathrm{X}$-ray powder diffraction (XRD) was used to check the formation and identify the compounds present in the obtained powders. The morphology and the particle size of the powders were examined by scanning electron microscopy (SEM). For calculating the yield of $\mathrm{ZnO}$ powder, the obtained precursors were calcined at $600^{\circ} \mathrm{C}$ for $2 \mathrm{~h}$. The calcined precursors were confirmed to only contain $\mathrm{ZnO}$. The yield of $\mathrm{ZnO}$ powder was calculated from the ratio of the weight of the calcined precursors to that of $\mathrm{ZnO}$ powder which can be theoretically obtained from the solution.

\section{Results and discussion}

\subsection{Effects of hydrothermal temperature on $\mathrm{ZnO}$ powder}

The precursors of $\mathrm{ZnO}$ powder were prepared by treating zinc nitrate with ammonia. After drying, white precipitates were obtained. The dried precipitates were confirmed to be zinc hydroxide by XRD. The precursors were then hydrothermally heated in pure water at 100,150 and $200^{\circ} \mathrm{C}$ for $2 \mathrm{~h}$. The XRD patterns of obtained powders are shown in Fig. 1. It is found that all specimens become zinc oxide powder with welldeveloped crystallinity. It reveals that zinc oxide powder was directly synthesized during the hydrothermal process. All diffraction peaks are assigned to $\mathrm{ZnO}$ as reported in JCPDS file [17], indicating that the produced powder was monophasic zincite with a hexagonal structure.

The microstructures of $\mathrm{ZnO}$ powder prepared at different heating temperature are shown in Fig. 2. It is observed that most of particles exhibit an ellipsoidal shape with a well dispersion state which is similar to that of the powder prepared by Chittofrati and Matijevic [16]. In addition, small particles with a rounded shape are also observed in the specimen hydrothermally treated at high temperatures. The average particle size was measured from the results in SEM micrographs. For the ellipsoidal particles, the mean value of the lengths in long and short axes was taken as the particle size. Fig. 3(a) illustrates the relation of the particle sizes versus the hydrothermal temperature. At 100 and $150^{\circ} \mathrm{C}$, the particle size of $\mathrm{ZnO}$ powder is around 1.25 $\mu \mathrm{m}$; however, it is reduced to $0.85 \mu \mathrm{m}$ when the reaction temperature increases to $200^{\circ} \mathrm{C}$. The yield of obtained powder is plotted in Fig. 3(b). This figure indicates that the yield of powder is around $82 \%$ after 100 and $150^{\circ} \mathrm{C}$ reactions; whereas it drops to $57 \%$ at $200^{\circ} \mathrm{C}$. The decrease in particle size as well as the production yield at $200^{\circ} \mathrm{C}$ is probably ascribed to the partial dissolution of $\mathrm{ZnO}$ powder at high pressure under hydrothermal conditions. The existence of small undissolved $\mathrm{ZnO}$ powder can be observed in Fig. 2(c).

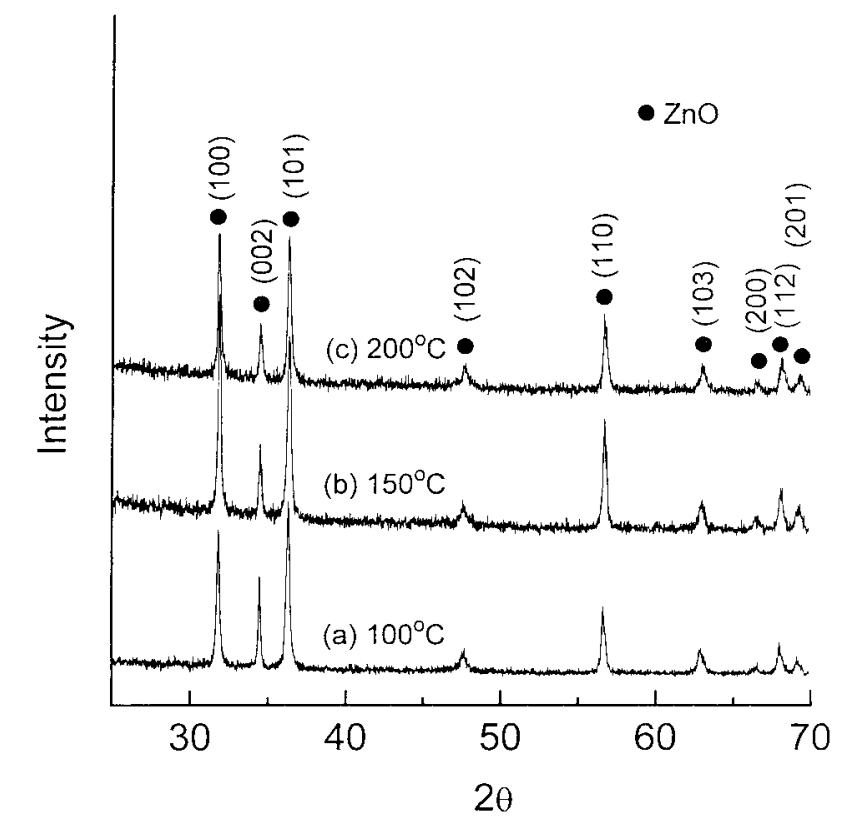

Fig. 1. X-ray diffraction patterns of $\mathrm{ZnO}$ powder hydrothermally prepared at (a) $100^{\circ} \mathrm{C}$, (b) $150^{\circ} \mathrm{C}$, and (c) $200^{\circ} \mathrm{C}$ for $2 \mathrm{~h}$. 

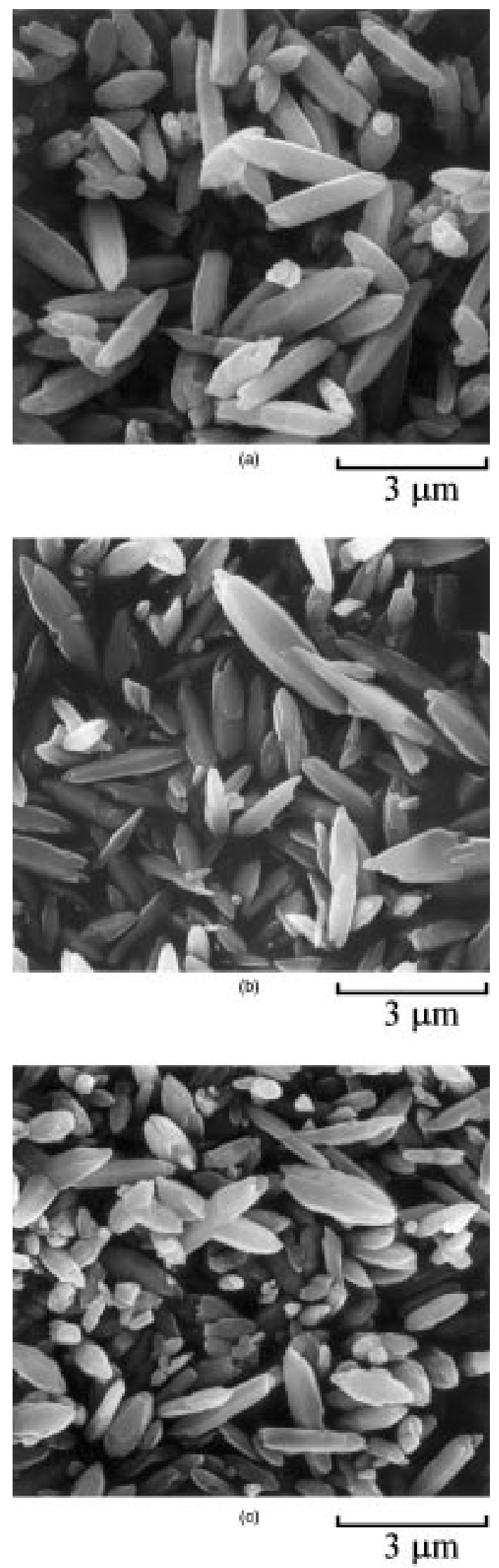

Fig. 2. Scanning electron micrographs of $\mathrm{ZnO}$ powder hydrothermally prepared at (a) $100^{\circ} \mathrm{C}$, (b) $150^{\circ} \mathrm{C}$, and (c) $200^{\circ} \mathrm{C}$ for $2 \mathrm{~h}$.

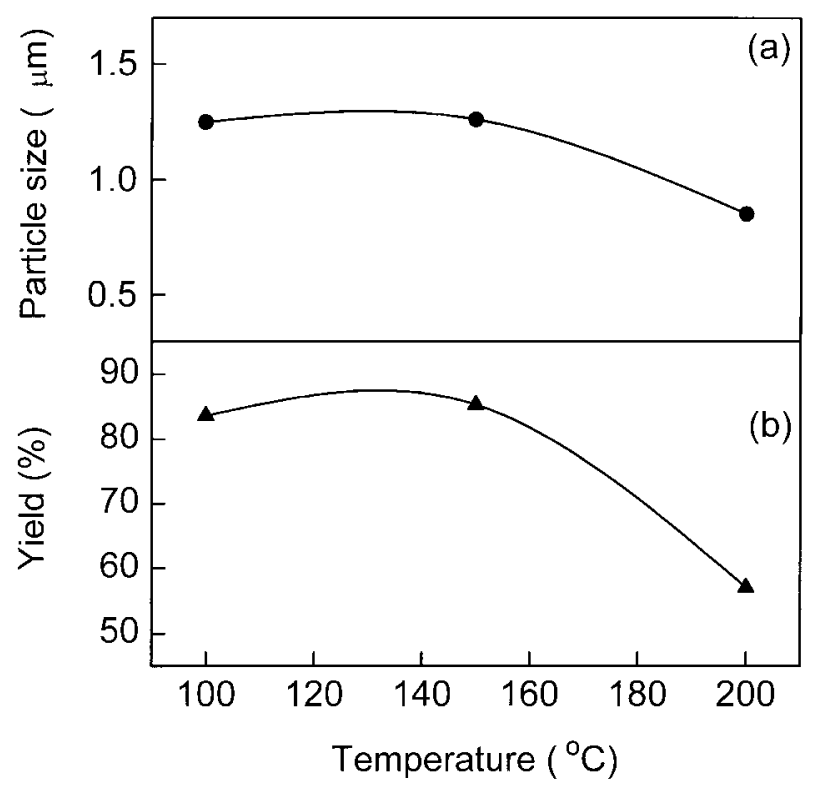

Fig. 3. (a) Particle size and (b) production yield of $\mathrm{ZnO}$ powder versus reaction temperature during hydrothermal processing.

\subsection{Effects of hydrothermal time on $\mathrm{ZnO}$ powder}

For examining the hydrothermal reaction time on the microstructure of $\mathrm{ZnO}$ powder, the reaction temperature was fixed at $100^{\circ} \mathrm{C}$, and the reaction time was prolonged from 0 to $2 \mathrm{~h}$. The hydrothermal reaction was performed in pure water. The reaction for $0 \mathrm{~h}$ at $100^{\circ} \mathrm{C}$ means that the hydrothermal reaction was ceased as soon as the temperature reached $100^{\circ} \mathrm{C}$ and the specimen was quickly cooled without any soaking. Based on the XRD analysis of obtained powder, $\mathrm{ZnO}$ has been confirmed in all specimens with well-crystallized structure similar to that shown in Fig. 1(a). These results indicate that $\mathrm{ZnO}$ powder can be rapidly prepared with $100^{\circ} \mathrm{C}$-hydrothermal treatment even without soaking at that temperature. The SEM observation indicates that these specimens exhibit similar ellipsoidal morphology. As seen in Fig. 4(a), the particle size does not significantly vary with the reaction time and is around 1.3 $\mu \mathrm{m}$. On the other hand, the yield of $\mathrm{ZnO}$ powder slightly increases with the reaction time from $76 \%$ at $0 \mathrm{~h}$ to $83 \%$ at $2 \mathrm{~h}$ [as shown in Fig. 4(b)]. From Fig. 4, it can be seen that $\mathrm{ZnO}$ is rapidly formed and crystallized at $100^{\circ} \mathrm{C}$ under hydrothermal environment. Prolonging the reaction time does not substantially enhance the crystal growth of $\mathrm{ZnO}$ powder.

In the other comparative experiment, the used precursors (zinc hydroxide) were analyzed by TGD and the result is shown in Fig. 5. In this curve, two steps of weight loss are observed, which are ascribed to the evaporation of absorbed water on precursors and the decomposition of zinc hydroxide, respectively. No weight loss occurs at temperature higher than $300^{\circ} \mathrm{C}$. $\mathrm{XRD}$ analysis confirmed that the crystalline $\mathrm{ZnO}$ powder 


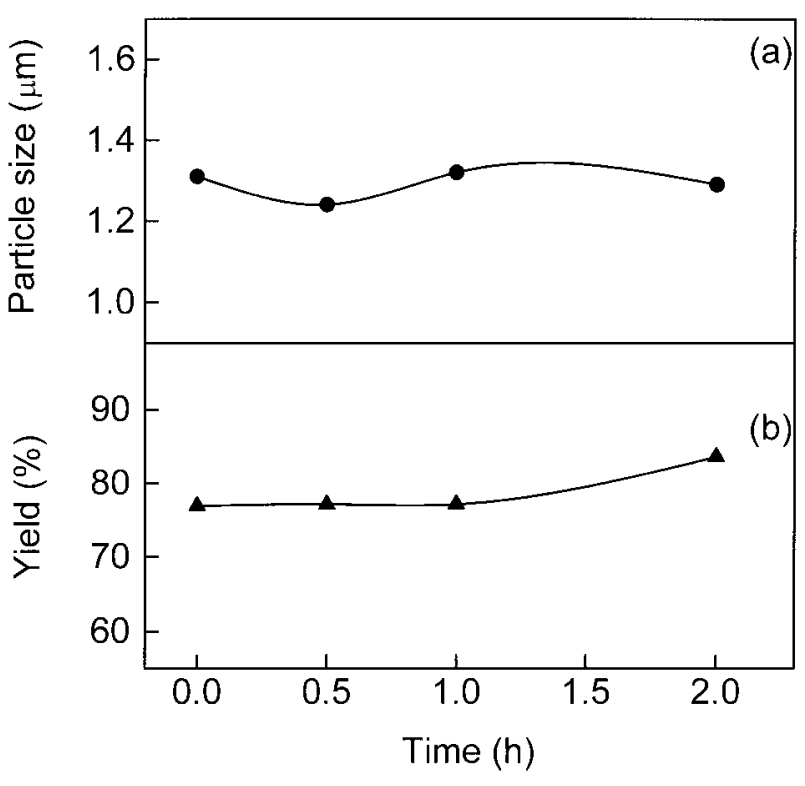

Fig. 4. (a) Particle size and (b) production yield of $\mathrm{ZnO}$ powder versus reaction time during hydrothermal processing at $100^{\circ} \mathrm{C}$.

was obtained at $300^{\circ} \mathrm{C}$. The above results indicate that in the conventional heating process, heating up to $300^{\circ} \mathrm{C}$ is required for preparing $\mathrm{ZnO}$ crystalline powder; whereas in the hydrothermal process, the heating temperature for preparation of $\mathrm{ZnO}$ powder is reduced as low as $100^{\circ} \mathrm{C}$ which is much lower than the temperature required in the conventional process.

\subsection{Effects of the pH of starting solutions on $\mathrm{ZnO}$ powder}

In order to understand the influence of $\mathrm{pH}$ of starting solutions on $\mathrm{ZnO}$ powder, we have systematically

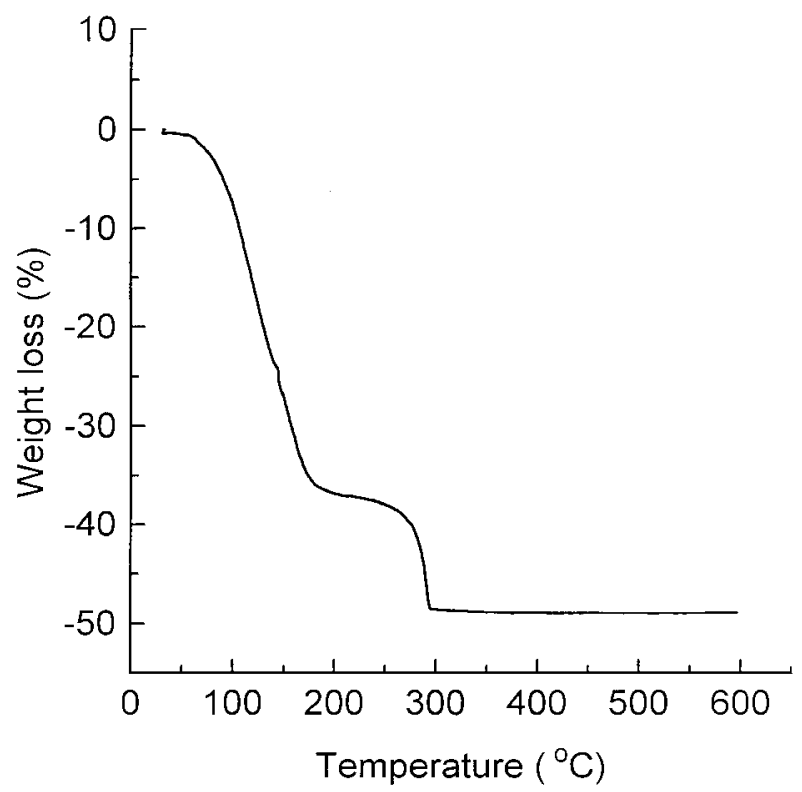

Fig. 5. Thermogravimetry analysis of zinc hydroxide prepared in the study. adjusted the $\mathrm{pH}$ of solutions from 9 to 12 prior to the hydrothermal treatment. The hydrothermal condition was set at $100^{\circ} \mathrm{C}$ without soaking. After adding ammonia into the precursors, it is found that the precursors are gradually dissolved into solution at $\mathrm{pH}>9$, and all precursors are completely dissolved when $\mathrm{pH}$ is $\geqslant 11$. The different state of precursors profoundly influences the formation of $\mathrm{ZnO}$ powder.

The XRD patterns of hydrothermally obtained $\mathrm{ZnO}$ powder at various $\mathrm{pH}$ are shown in Fig. 6. It is found that the peak intensity for obtained powder tends to increase with the increase in $\mathrm{pH}$. Since the weight of samples in XRD analysis is nearly the same, the increase in the intensity of diffraction peaks is attributed to the increase in the crystallinity of the obtained powder. It is also found that the ratio of the intensity of (100) peak to that of (002) peak of $\mathrm{ZnO}$ powder tends to increase as $\mathrm{pH}$ increases. As is shown in Fig. 7 later, in the high $\mathrm{pH}$ range, the morphology of $\mathrm{ZnO}$ powder becomes rodlike. It is considered that the variation of the $(100) /(002)$ intensity ratio is caused by the shear stress on the powder compacting in the XRD holder to induce the rodlike particles to arrange their long axis parallel to the direction of the compacting force. TEM analysis also confirmed that $\mathrm{ZnO}$ powder is monocrystalline; therefore, the diffraction intensity of $\mathrm{ZnO}$ is varied by the orientation of powder.

The SEM micrographs of $\mathrm{ZnO}$ powder prepared at different $\mathrm{pH}$ are presented in Fig. 7. At $\mathrm{pH}=9$, particle shape of $\mathrm{ZnO}$ powder is round. At $\mathrm{pH}=10$, zinc powder exhibits both of the rounded and ellipsoidal shapes. When $\mathrm{pH}$ becomes higher than 11, the surface of particles becomes smoother, and the shape of particles varies

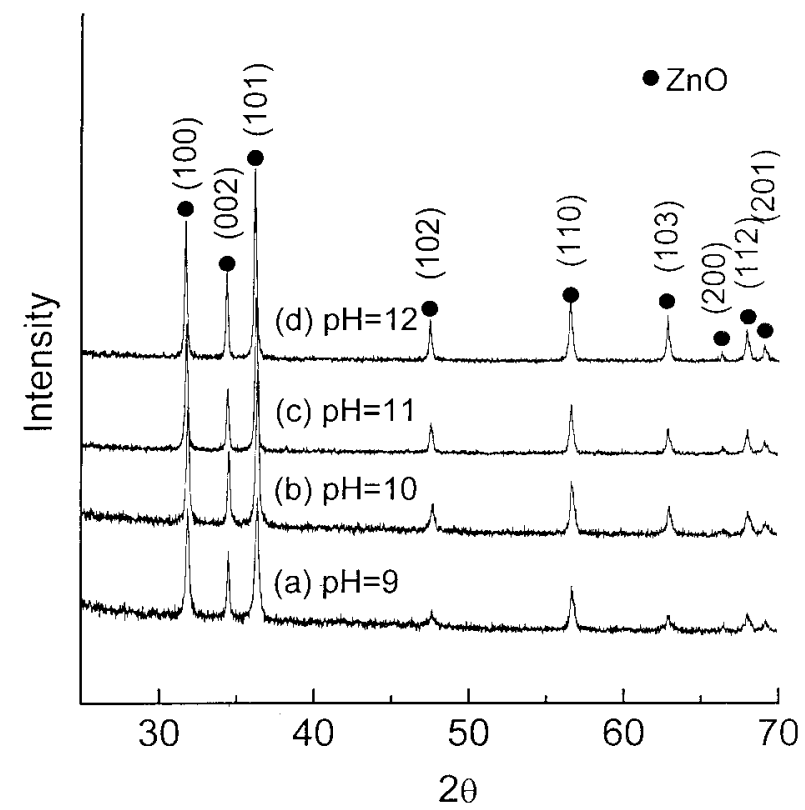

Fig. 6. X-ray diffraction patterns of $\mathrm{ZnO}$ powder hydrothermally prepared at $\mathrm{pH}=$ (a) 9, (b) 10, (c) 11, and (d) 12 . 

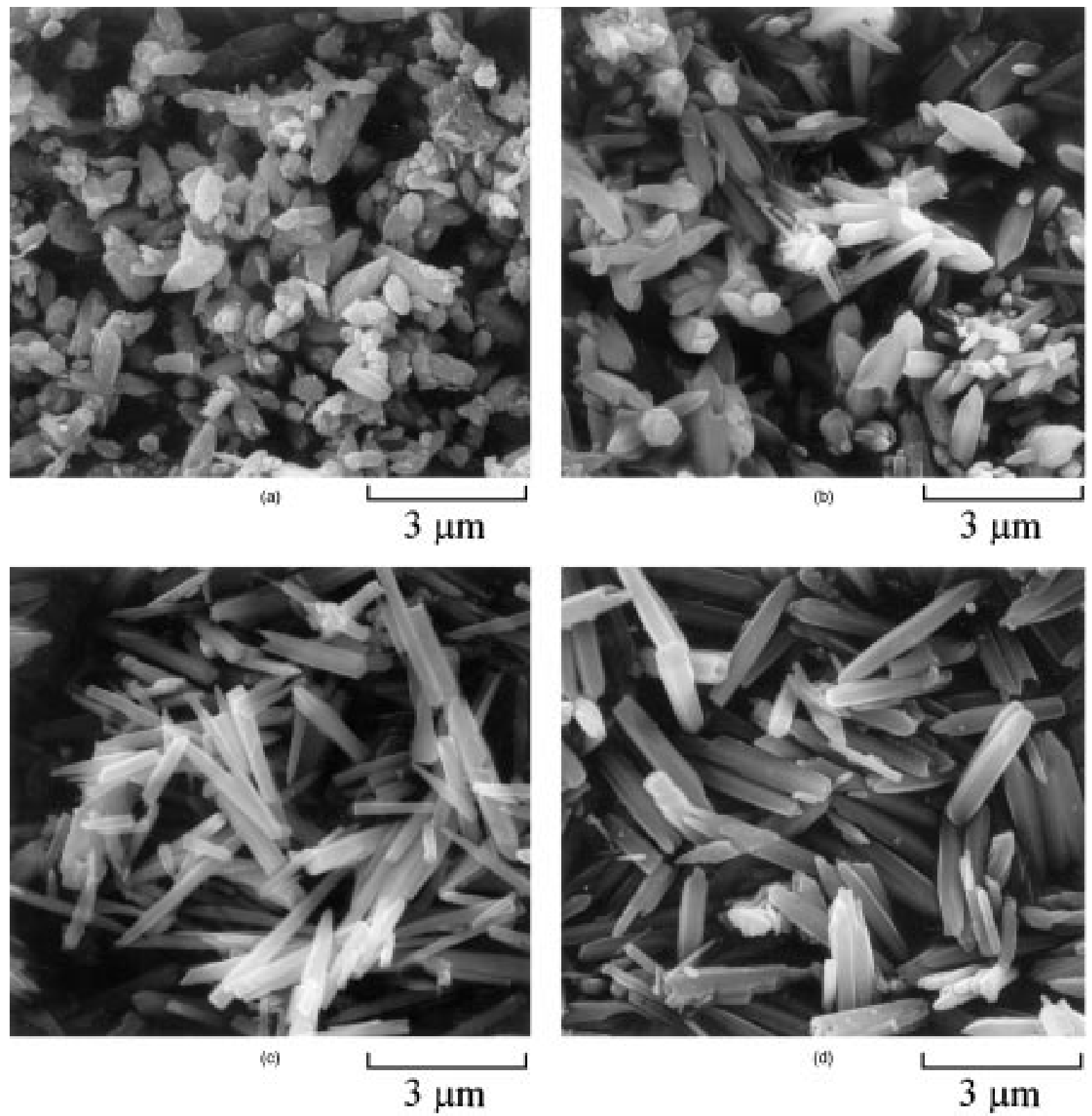

Fig. 7. Scanning electron micrographs of $\mathrm{ZnO}$ powder hydrothermally prepared at $\mathrm{pH}=$ (a) 9, (b) 10, (c) 11, and (d) 12 .

to rod-like. The aspect ratio of $\mathrm{ZnO}$ particles is found to increase by raising the $\mathrm{pH}$ of solution. This high aspect ratio of $\mathrm{ZnO}$ powder prepared during the range of high $\mathrm{pH}$ is related to its preferential growth in $a$-axis.

Fig. 8 illustrates the particle size and the yield of $\mathrm{ZnO}$ powder versus the $\mathrm{pH}$ of the starting solution. In this figure, region $\mathrm{A}$ and region $\mathrm{B}$ present the precursors partially dissolved and completely dissolved in ammonia solution, respectively. It is observed that the particle size of $\mathrm{ZnO}$ powder increases with increasing $\mathrm{pH}$ as shown in Fig. 8(a). As seen in Fig. 8(b), the yield of $\mathrm{ZnO}$ powder remains almost the same in region A. However, in region $\mathrm{B}$ the yield of production markedly drops with a rise in $\mathrm{pH}$. When $\mathrm{pH}$ reaches $12.5, \mathrm{ZnO}$ powder could not be obtained (the yield $=0$ ).
According to the above results, it is found that the crystallinity, morphology, and production yield of $\mathrm{ZnO}$ markedly depends on the $\mathrm{pH}$ of starting solutions. Since the used precursor-zinc hydroxide is an amphoteric species, adding ammonia tends to dissolve this precursor. In region $\mathrm{A}$ with $\mathrm{pH}<11$, the zinc hydroxide precursors are partially dissolved. Therefore, $\mathrm{ZnO}$ powder is nucleated in a heterogeneous system. On the other hand, in region $\mathrm{B}$ with $\mathrm{pH} \geqslant 11$, all zinc hydroxide precursors are dissolved and a clear solution is formed, so that $\mathrm{ZnO}$ powder is nucleated in a homogeneous solution. Thus different nucleation states take place in regions $\mathrm{A}$ and region $\mathrm{B}$.

In general, the probability of nucleation in the homogeneous clear solution is lower than that in heterogeneous 


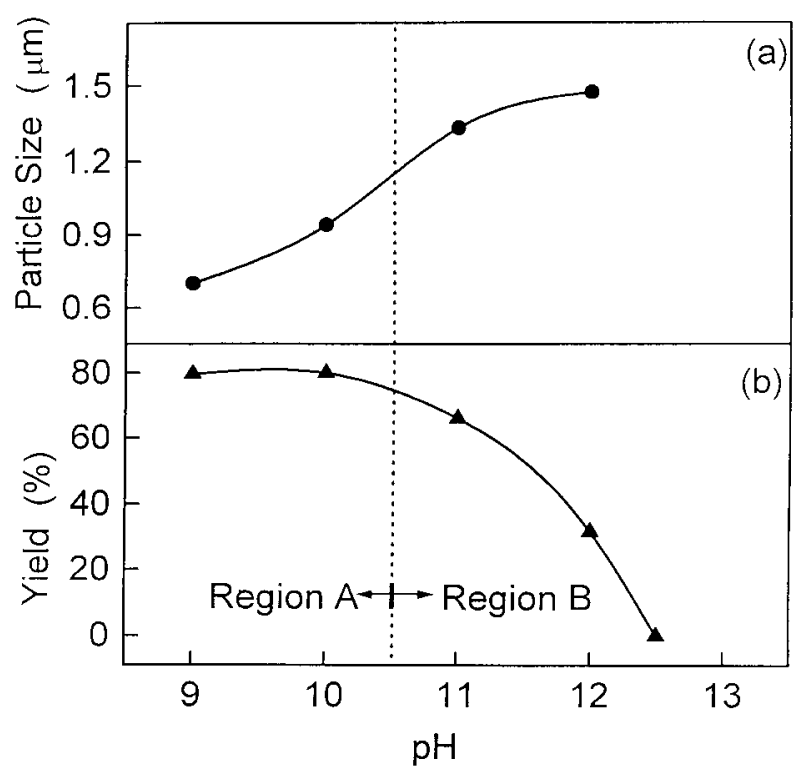

Fig. 8. (a) Particle size and (b) production yield of $\mathrm{ZnO}$ powder versus $\mathrm{pH}$ value in the starting solutions.

solution. Therefore, the number of formed nuclei in region $\mathrm{B}$ is reduced, and the yield of $\mathrm{ZnO}$ powder in region $\mathrm{B}$ is lower than that in region $\mathrm{A}$. The decrease of the yield with increasing the $\mathrm{pH}$ in region $\mathrm{B}$ is because $\mathrm{ZnO}$ is also an amphoteric compound, it will dissolve in strong alkaline solution. Therefore, the high $\mathrm{pH}$ environment is unfavorable for the formation $\mathrm{ZnO}$. When $\mathrm{pH}$ of the solution reaches to 12.5 , it is difficult to get supersaturated concentration and hence no nucleated $\mathrm{ZnO}$ particles would be formed. On the other hand, the particle size is found to increase by raising $\mathrm{pH}$. This is ascribed to the increase in the zinc ion concentration in bulk solution when more zinc hydroxide precursors are dissolved when the $\mathrm{pH}$ of solutions increases, and more zinc atom are supplied to $\mathrm{ZnO}$ nuclei, thereby resulting in an increase in the particle size of formed powder. The different nucleation state also induces the significant variation in the morphology of $\mathrm{ZnO}$ powder. In region $\mathrm{B}$ where homogeneous nucleation occurs, the zinc atoms present in homogeneous solution have a large freedom to move and array themselves to a more stable energy state, thereby producing rod-like particles. Therefore, for better governing the morphology of $\mathrm{ZnO}$ powder, the nucleation state during hydrothermal processing should be precisely controlled.

\section{Conclusions}

In conclusion, the hydrothermal technique is proved to be one successful method to prepare crystalline zinc oxide powder by using ammonia as the base source at temperature $\geqslant 100^{\circ} \mathrm{C}$. On comparison with the conventional heating process, the developed process effectively reduces the temperature by $200^{\circ} \mathrm{C}$ for synthesizing $\mathrm{ZnO}$ powder. During the hydrothermal processing, $\mathrm{ZnO}$ particles are rapidly formed and grown as soon as the temperature reaches $100^{\circ} \mathrm{C}$. Further prolonging the reaction time at $100^{\circ} \mathrm{C}$ does not significantly vary the particle size of obtained powder. On the other hand, increase in the reaction temperature slightly reduces the particle size as well as the production yield of $\mathrm{ZnO}$ powder. It is found that the characteristics of $\mathrm{ZnO}$ powder profoundly depends on the $\mathrm{pH}$ of the starting solutions. When the $\mathrm{pH}$ of the starting solution increases from 9 to 12, the starting solution varies from a heterogeneous solution state to a homogeneous state, and the morphology of obtained $\mathrm{ZnO}$ powder changes from an ellipsoidal shape to a rod-like shape. In addition, the crystallinity and particle size of $\mathrm{ZnO}$ powder increase with a rise in the $\mathrm{pH}$ of solutions. However, the yield of production reduces with that. The variation of microstructure and characteristics of obtained $\mathrm{ZnO}$ powder with $\mathrm{pH}$ is attributed to different nucleation mechanisms occurring in the hydrothermal reaction.

\section{Acknowledgement}

Financial support for this work from the National Science Council, Taiwan, the Republic of China through Grant NSC 86-2745-E002-0002R is gratefully acknowledged.

\section{References}

[1] S.I. Hirano, Hydrothermal processing of ceramics, Am. Ceram. Soc. Bull. 66 (1987) 1342-1344.

[2] T.R.N. Kutty, R. Vivekanandan, S. Philp, Precipitation of ultrafine powders of zirconia polymorphs and their conversion of $\mathrm{MZrO}_{3}(\mathrm{M}=\mathrm{Ba}, \mathrm{Sr}, \mathrm{Ca})$ by the hydrothermal method, J. Mater. Sci. 25 (1990) 3649-3658.

[3] G.A. Rossetti Jr., D.J. Watson, R.E. Newnham, J.H. Adair, Kinetics of the hydrothermal crystallization of the perovskite lead titanate, J. Cryst. Growth 116 (1992) 251-259.

[4] H. Kumazawa, T. Kagimoto, A. Kawabata, Preparation of barium titanate ultrafine particles from amorphous titania by a hydrothermal Method and specific dielectric constants of sintered discs of the prepared particles, J. Mater. Sci. 31 (1996) 2599-2602.

[5] P.K. Dutta, J.R. Gregg, Hydrothermal synthesis of tetragonal barium titanate, Chem. Mater. 4 (1992) 843-846.

[6] Y.C. Zhou, M.N. Rahaman, Hydrothermal synthesis and sintering of ultrafine $\mathrm{CeO}_{2}$ powders, J. Mater. Res. 8 (1993) 1680-1686.

[7] C.H. Lu, N. Chyi, Fabrication of fine lead metaniobate powder using hydrothermal processes, Mater. Lett. 29 (1996) 101-105.

[8] C.H. Lu, S.Y. Lo, Lead pyronibate pyrochlore nanoparticles synthesized via hydrothermal processing, Mater. Res. Bull. 32 (1997) 371-378.

[9] C.H. Lu, W.J. Hwang, Preparation of $\mathrm{Pb}(\mathrm{Zr}, \mathrm{Ti}) \mathrm{O}_{3}-\mathrm{Pb}\left(\mathrm{Ni}_{1 / 3^{-}}\right.$ $\left.\mathrm{Nb}_{2 / 3}\right) \mathrm{O}_{3}$ solid solution powder from hydrothermally-treated precursors, Mater. Lett. 27 (1996) 229-232.

[10] S.M. Haile, D.W. Johnson, G.H. Wiseman, H.K. Bowen, Aqueous precipitation of spherical zinc oxide powders for varistor applications, J. Am. Ceram. Soc. 72 (1989) 2004-2008. 
[11] M.E.V. Costa, J.L. Baptista, Characterization of zinc oxide powder precipitated in the presence of alcohols and amines, J. Eur. Ceram. Soc. 11 (1993) 275-281.

[12] T. Trindade, J.D. Pedrosa de Jesus, P. O'Brien, Preparation of zinc oxide and zinc sulfide powders by controlled precipitation from aqueous solution, J. Mater. Chem. 4 (1994) 16111617.

[13] T.Q. Liu, O. Sakurai, N. Mizutani, M. Kato, Preparation of spherical fine $\mathrm{ZnO}$ particles by the spray pyrolysis method using ultrasonic atomization techniques, J. Mater. Sci. 21 (1986) 36983702 .
[14] M. Andres-Verges, M. Martinez-Gallego, Spherical and rod-like zinc oxide microcrystals: morphological characterization and microstructural evolution with temperature, J. Mater. Sci. 27 (1992) 3756-3762.

[15] H. Nishizawa, T. Tani, K. Matsuoka, Crystal growth of $\mathrm{ZnO}$ by hydrothermal decomposition of Zn-EDTA, J. Am. Ceram. Soc. 67 (1984) C-98-C-100.

[16] A. Chittofrati, E. Matijevic, Uniform particles of zinc oxide of different morphologies, Coll. Surf. 48 (1990) 65-78.

[17] Joint Committee on Powder Diffraction Standards, Powder Diffraction File, Card No. 36-1451, Swarthmore, PA. 